\title{
Resentimiento y verdad. Sobre la réplica de Améry a Nietzsche
}

\author{
JULIÁN MARRADES \\ Universidad de Valencia
}

RESUMEN. En su Genealogía de la moral, Nietzsche situó el resentimiento del débil en la base de la moralización de los valores originales del fuerte - entre ellos, la crueldad inherente a la afirmación de la vidaque transformó éstos en negativos. A esta idea del resentimiento como un mecanismo esencialmente distorsionador se opone Jean Améry, víctima de la violencia nazi, en Más allá de la culpa y la expiación (1966), donde reivindica su resentimiento hacia los verdugos y sus cómplices como un instrumento de verdad para exigirles el reconocimiento de su crimen y la negación de su condición de verdugos. El objetivo del artículo es reconstruir la trama conceptual en que se articula la divergencia entre Améry y Nietzsche, mostrando los diferentes compromisos ontológicos sobre la moral que sustentan sus respectivas concepciones del resentimiento.

Gilles Deleuze cifra el proyecto más general de Nietzsche en introducir en la filosofía los conceptos de sentido y valor en la forma de una crítica dirigida tanto contra quienes censuran las cosas en nombre de valores ya establecidos como contra quienes hacen derivar éstos de pretendidos
ABSTRACT. In his Genealogy of Morals Nietzsche located the weak's resentment on the basis of the moralization of the strong's original values - among them the inherent cruelty of life's strengtheningwich transformed in negative values. In Beyond guilt and expiation (1966) Jean Améry, a victim of nazi's violence, opposes to this idea of resentment as a mechanism essentially distortioning. He claims his resentment against executioners and their accomplices as an instrument of truth in view of demanding them the admission of their crime and the negation of their executioners' condition. The paper's aim is to reconstrue the conceptual plot in wich the divergence between Améry and Nietzsche is articulated, showing at the same time the different ontological commitments on moral that hold up their conceptions of resentment.

hechos objetivos ${ }^{1}$. Se trata, por consiguiente, de una crítica radical, pues no se basa en un fundamento dado, y total, ya que afecta al dominio entero de las grandes palabras cultivadas por la cultura europea a lo largo de su historia: ser, verdad, bien, belleza, amor, conocimiento, 
lenguaje, utopía, sujeto. Uno de los falsos ídolos que el martillo de Nietzsche pretende hacer pedazos es la moral. Su sospecha de que tras los ideales de la virtud se esconden el fraude y la impotencia ha trascendido el estrecho ámbito de la filosofía profesional para instalarse en la conciencia colectiva en que vagamente se refleja la crisis de la modernidad.

En el origen de este ensayo se encuentra la insolencia de una voz disonante. En su libro Más allá de la culpa y la expiación, publicado en 1966, Jean Améry, judío austríaco que en 1940 se unió a la resistencia antinazi en Bélgica y, tras ser arrestado en 1943 por la Gestapo, fue internado hasta 1945 en Auschwitz describe su condición de víctima de la violencia. Enfrentándose a Nietzsche, Améry reivindica ahí como una actitud moral el resentimiento que siente contra los verdugos de ayer y sus pasivos cómplices de hoy.

Para tratar de reconstruir la trama conceptual en que se teje la divergencia entre ambos, era imprescindible hallar un terreno común. Parecía prudente, a tal efecto, no conceder demasiado peso a las diferencias idiosincrásicas - la autocomprensión de la filosofía de Nietzsche como testimonio de sí mismo, y de sí mismo como un destino; la reflexión de Améry como elaboración de una experiencia límite- No resultó, sin embargo, difícil hallar en los propios textos de Améry y de Nietzsche la base requerida para articular filosóficamente el debate, pues los dos vinculan el problema del resentimiento con la cuestión del estatuto ontológico de lo moral. La pregunta acerca de si hay o no hay hechos morales es común a ambos. Y también lo es la forma de conectar conceptualmente las respuestas que dan a esta pregunta con sus respectivos puntos de vista acerca de la naturaleza del resentimiento. El propósito de este ensayo es contrastar las dos posiciones, a fin de mostrar que la genealogía nietzscheana de la moral no da razón del tipo de conexión entre resentimiento y moralidad que Améry descubre en su propia experiencia como víctima de la violencia.

I

En el otoño de 1946 Stig Dagerman, escritor sueco de 23 años, emprendió un viaje por la Alemania en ruinas como corresponsal del periódico Expressen. Su mirada sobre aquellos alemanes derrotados, muchos de los cuales confesaban que en tiempo de Hitler vivían mejor, quedó reflejada en un reportaje publicado en 1947 con el título Otoño alemán. Uno de los aspectos más aleccionadores del reportaje es el referido a la actuación de los vencedores en relación con los colaboracionistas del régimen hitleriano. Dagerman denuncia el comportamiento cínico de las potencias aliadas, cuyo discurso condenaba el nazismo en abstracto mientras eludía depurar responsabilidades concretas por las atrocidades cometidas, y cuya política de desnazificación tendía más a favorecer la disimulación de los valores nazis que su verdadera erradicación. Consecuencia de ello fue la pronta decepción de muchas víctimas, que vieron defraudada su esperanza en que los vencedores se comprometieran en una regeneración democrática de Alemania. De este sector de los vencidos dice Dagerman lo siguiente:

Existe en Alemania un número considerable de antinazis sinceros más decepcionados, más apátridas y más derrotados que cualquiera de los simpatizantes nazis. Decepcionados, porque la liberación no fue tan radical como esperaban; apátridas, porque no quieren solidarizarse ni con el descontento alemán -en cuyos ingredientes creen ver demasiado nazismo encubierto - ni con la política aliada - cuya indulgencia para con los antiguos nazis ven con consternación-, y finalmente derrotados, porque, por un lado, se preguntan si ellos como alemanes pueden tener alguna participación en 
la victoria final de los aliados, y por otro lado porque no están tan convencidos de que, como antinazis, no tengan una parte de responsabilidad en la derrota alemana. Se han condenado a sí mismos a una pasividad total, ya que la actividad significa cooperar con elementos dudosos a los que aprendieron a odiar durante doce años de opresión?

Jean Améry no era alemán, pero formaba parte de las víctimas del nazismo que se habrían visto sustancialmente reflejadas en esta descripción de Dagerman. Durante algún tiempo, acabada la guerra, pareció que las potencias vencedoras estaban decididas no sólo a castigar a los criminales nazis que habían sobrevivido, sino también a impedir que Alemania pudiera amenazar nunca más la paz mundial. Se le permitiría desarrollarse en el plano económico, pero se le negaría toda capacidad de reorganizarse autónomamente en el plano político y militar. Quedaba así patente que la acusación sobre lo ocurrido en la Alemania nazi no se reducía a los jerarcas del régimen, sino que se hacía extensiva de algún modo al país entero, que había consentido durante años ese régimen. Améry confiesa, a propósito de esto: «Por primera vez en mi vida compartía el estado de ánimo de la opinión pública que resonaba a mi alrededor. Me sentía muy a gusto en el papel absolutamente insólito de conformista» ${ }^{3}$. Su sobrevenido conformismo arraigaba en la convicción de que sobre el pueblo alemán pesaba una culpa colectiva que sólo podría borrarse mediante una expiación también colectiva.

Pero este entendimiento con el mundo duró poco. Muy pronto, los vencedores dieron a entender que en sus planes de recuperación para Alemania no figuraba limitar su soberanía, sino restablecer su poder dentro del bando de los vencedores. El destino de Alemania no era ser un país vencido, sino convertirse en un país aliado. Los políticos alemanes del momento, la mayoría de los cuales no se habían distinguido en la lucha de la resistencia, se lanzaron con entusiasmo a la empresa de vincular Alemania a una nueva Europa, en la cual no todos los elementos de la Europa hitleriana resultaban desechables. Dentro de ese clima de reconstrucción, ¿qué lugar había para una expiación general? Lo importante era superar los traumas que había dejado la etapa del Tercer Reich. A esta superación contribuyeron también algunos destacados intelectuales judíos que promovieron un pathos de perdón y reconciliación. No resulta, pues, extraño que la inmensa mayoría de la población adulta dejase de mirar hacia el pasado y se embarcara en una nueva singladura de autoafirmación nacional.

Como ejemplo de esta actitud emergente entre los oficialmente derrotados refiere Améry una conversación que mantuvo con un comerciante del sur de Alemania mientras desayunaba en un hotel: «Aquel hombre intentaba convencerme, no sin antes informarse cortésmente de si era judío, de que en su país no existía odio racial. Aseguraba que el pueblo alemán no guardaba rencor al judío; como prueba aludía a la generosa política de reparación promovida por el gobierno, como, por lo demás, reconocía el joven Estado de Israel. Yo me sentía detestable ante aquel tipo de ánimo tan equilibrado» ${ }^{4}$. En la medida en que la actitud de su interlocutor podía considerarse representativa, revelaba la nueva situación espiritual del ciudadano medio alemán: no sólo no se sentía culpable de haber consentido o colaborado con la política criminal de Hitler, sino que se sentía complacido de su superioridad moral, pues los combatientes de la resistencia y las víctimas judías eran rencorosos, y él no. Asî pues, el pueblo alemán no estaba entre los vencidos, sino entre los vencedores; y las víctimas del nazismo, lejos de haberse reparado la injusticia cometida con ellas, continuaban siendo unos vencidos. A Améry se le impuso esta definitiva evidencia: «Quienes habíamos creído que la vic- 
toria de 1945 era, al menos en una pequeña parte, también la nuestra, nos vimos obligados a revocarla» 5 .

El resentimiento surgió en él al advertir, tiempo después de acabada la guerra, ese distanciamiento de la sociedad alemana respecto a su participación en los crímenes cometidos durante el régimen nazi. No había aflorado aún en el momento de ser liberado de Bergen-Belsen ${ }^{6}$. Por tanto, no fue una reacción inmediata a la violencia padecida, sino una respuesta a la actitud distorsionadora de esa gran mayoría de alemanes que rehuyeron su parte de responsabilidad en los crímenes y se consideraron a sí mismos inocentes - pues ellos nada habían hecho y, además, estaban dispuestos a restañar las heridas, a superar el pasado-, e incluso víctimas del odio y del rencor de las víctimas. En consecuencia, no admitieron siquiera la posibilidad de ser acusados por ellas, sino que se convirtieron en sus acusadores.

Améry no responde a esa acusación tratando de desactivar los supuestos motivos en que se basa (por ejemplo, reprimiendo el odio que le provoca). Por el contrario, asume el rencor que se le reprocha ${ }^{7}$, a fin de utilizarlo como un medio para desenmascarar la distorsión de esa sociedad que, desde el momento en que no reconoce su deuda para con las víctimas, se ha alineado con los verdugos. Él sabe que su pretensión choca con algunas concepciones teóricas que han desacreditado el resentimiento como un estado irracional ligado, precisamente, a actitudes distorsionadoras. De ahí la necesidad que siente de justificar su resentimiento, pues sólo así podrá hacer comprender a sus destinatarios que tiene razones para sentirlo y que está legitimado para emplearlo como arma de desenmascaramiento, como instrumento de verdad. Esta tarea de legitimación se plantea en el modo de una confrontación con dos visiones establecidas: la clínica y la filosófica. «Mi objetivo es describir la condición subjetiva de víctima. Mi contri- bución consiste en el análisis retrospectivo del resentimiento. Lo que me encomiendo es la justificación de un estado psíquico que es condenado igualmente por moralistas como por psicólogos: los primeros lo juzgan una mácula, los segundos lo consideran una suerte de morbo» 8 .

El resentimiento de la víctima de la violencia es una reacción contra el verdugo que surge de la conciencia de que el daño padecido es imborrable. La víctima sabe que no puede volver a ser el que fue $\mathrm{y}$, sin embargo, tampoco quiere olvidar. Hay en esta actitud algo antinatural. Pues, en tanto que orientar la propia vida hacia el futuro es una actitud natural del hombre, el resentimiento de la víctima de la violencia aparece como el reverso de esta actitud, ya que la clava a su pasado y bloquea la única salida positiva, que es la que mira hacia delante. El rencor de la víctima tiene algo de absurdo: quiere cancelar el pasado al mismo tiempo que se fija a él. No es, pues, extraño que la moderna psicología vea en esa actitud un síntoma de desquiciamiento. El resentimiento vincula a la víctima de tal modo al dolor que padeció, que la orientación general de su vida queda trastocada. El antídoto clínico consistirá en tratar de liberarla de la sujeción a su pasado, a fin de que tome las riendas de su propia vida y la dirija hacia el futuro.

Améry reconoce que su sentido del tiempo está trastocado y que, examinado por la mirada objetiva de la ciencia, sólo puede verse en él a un ser desquiciado. Lo que no acepta es que esa mirada tenga la última palabra sobre su condición desquiciada. Por el contrario, afirma que la deformación que ha dejado en su persona la violencia padecida es «expresión de una humanidad con un rango moral e histórico superior» ${ }^{9}$ a la salud de esa gente que tiene el buen gusto de fomentar proyectos éticos de reconciliación nacional a base de no hurgar en el pasado. A la templanza de estos sanos que construyen el edificio de la reconciliación entre víctimas y verdu- 
gos sobre los cimientos de la desmemoria contrapone Améry su odio a esa reconciliación como un síntoma de salud moral, pues es una reacción proporcionada al falseamiento de la realidad por parte de esa sociedad industriosa y decente.

Al defender el valor moral de su resentimiento, Améry se enfrenta expresamente a Nietzsche ${ }^{10}$. Ciertamente, el filósofo de Sils-Maria atribuyó un significado moral al resentimiento, pero en un sentido opuesto al de Améry. Pues así como para éste el valor moral de su resentimiento reside en su dimensión de verdad, Nietzsche vinculó el resentimiento a toda una moral -la moral judeocristiana del amor y sus secuelas modernas - que, a su juicio, se basaba en un falseamiento sistemático de valores genuinos.

El papel que Nietzsche atribuye al resentimiento en el surgimiento de esa moral se halla en el modo específico como opera en la comparación valorativa del débil con el fuerte. El individuo fuerte tiene una conciencia inmediata de su propio valor que se traduce en una seguridad espontánea que no necesita justificarse ante sí ni ante los demás. Su sentimiento de autoafirmación, su voluntad de poder, es constituyente de su ser «bueno», mientras que lo carente de seguridad e impotente - todo aquello que encarna el individuo débil- es constituido por su juicio como «malo». El débil, por el contrario, sólo aprehende su propio valor reflejamente, a través de su comparación con el fuerte. Como esa comparación está teñida de impotencia, percibe siempre el propio valor como inferior al del fuerte. Y como esa percepción le resulta insoportable, intenta apaciguarla mediante procesos de autoengaño conducentes, ya sea a rebajar las cualidades valiosas del fuerte o a cegarse a ellas, ya sea a falsear los valores mismos a la luz de los cuales las cualidades del otro aparecen valiosas. El resentido que ve en otros la dicha, el poder o el talento, $\mathrm{y}$, sintiéndose atraído por tales valores - lo cual implica que en el fondo los considera positivos-, se siente impotente para conseguirlos, trata de compensar su debilidad rebajando esas cualidades y desatando impulsos de rechazo o enemistad contra sus portadores. Pero puede ir todavía más lejos, y llegar incluso a variar su juicio sobre los valores mismos, fingiéndose que no estima los valores que deseaba y no podía conseguir, y que estima los contrarios. Aquí el resentimiento no se dirige a disimularse los valores positivos del fuerte, sino a convertir esos valores positivos en negativos, de manera que los valores positivos pasen a ser los opuestos.

Esta transvaloración (Umwertung) de los valores de los fuertes por parte de los débiles es la obra maestra del resentimiento. Mientras los plebeyos consideraron como positivos los valores de los nobles que ellos no podían alcanzar, su rencor dio cauce a sentimientos de envidia, odio y venganza que atestiguaban la estima o admiración que sentían por aquellos valores. Pero, bajo el influjo del resentimiento, la inversión llegó a afectar a los valores mismos, de manera que aquellas cualidades de los débiles que ellos mismos consideraban malas conforme a la estimativa de los fuertes (la pobreza, la debilidad, el sufrimiento, etc.) pasaron a ser apreciadas como valores positivos. Como consecuencia de esta inversión, lo que los fuertes consideraban bueno pasó a ser considerado malvado (böse), lo malo (schlecht) pasó a ser considerado bueno, y los fuertes dejaron de ser tenidos como dignos de odio y venganza, y pasaron a ser considerados como dignos de lástima y compasión, bajo el supuesto de que poseían no bienes, sino males "

\section{II}

En la concepción nietzscheana del resentimiento hay varios elementos que interesa retener, de cara a la réplica que Améry le plantea. En primer lugar, al considerarlo 
como una actitud esencialmente reactiva, Nietzsche sitúa el resentimiento en el marco de la lógica de la compensación, caracterizándolo como una venganza ficticia mediante la cual el impotente se resarce de la ofensa percibida. Y como la satisfacción que obtiene deriva de esa compensación, el débil está interesado en mantener viva la llama de su resentimiento. Es importante también destacar su función tergiversadora, que se manifiesta en un doble aspecto: por un lado, en el falseamiento de la manera auténtica de valorar propia del fuerte, invirtiéndola de tal modo que los valores negativos pasen a ser considerados afirmativos; $y$, por otro lado, en la autodisimulación del propio resentimiento, en virtud de la cual el hombre rencoroso no se reconoce como tal. En lo que sigue trataré de mostrar que ninguno de estos rasgos está presente en el resentimiento de Améry.

Comenzaré por el último. Llama la atención desde el primer momento que Améry no oculte su resentimiento. Al contrario, lo confiesa abiertamente: «Hablo como víctima y escudriño mis resentimientos. No es una empresa placentera, ni para el lector ni para el autor, y tal vez haría bien si comenzara disculpándome por mi falta de tacto" ${ }^{12}$. No cabe, pues, acusarle de disimular su condición de resentido. Esto es particularmente relevante si se tiene en cuenta que aferrarse a su resentimiento es para Améry una experiencia dolorosa, una forma de hacerse violencia a sí mismo. Algunas víctimas del nazismo que sobrevivieron a situaciones límite en los campos de exterminio han atestiguado que, al verse liberados, sintieron una necesidad casi compulsiva de olvidar los traumas sufridos ${ }^{13}$. En este sentido, y puesto que el resentimiento contribuye a mantener abierta la herida, quien lo ha experimentado ha debido de sentir también la tentación de acallarlo. Por ello, sólo haciendo frente a ese impulso mediante una voluntad de resistencia al olvi- do han logrado algunos supervivientes de esas catástrofes humanas dar testimonio de lo ocurrido. Asumir su resentimiento es la forma que toma en Améry su resistencia a disimular el conflicto irresuelto con los criminales nazis y sus cómplices pasivos, su «personal protesta contra la cicatrización del tiempo como proceso natural» ${ }^{14}$. En lugar de reprimir o sublimar su rencor, Améry rechazó toda componenda para vivir en falsa paz consigo mismo y con los demás. Lejos, pues, de ser una maniobra de distorsión, su resentimiento es un antídoto contra la tentación de falseamiento.

Pero Améry no sólo confiesa su resentimiento, sino que también lo reivindica. Sabemos - como también lo sabía Améry- cuál es el significado oculto que Nietzsche atribuyó a la función reivindicativa del resentimiento: es la reacción de aquellos seres a quienes les está vedada la auténtica acción, para desquitarse de las ofensas de los fuertes únicamente con una venganza imaginaria ${ }^{15}$. El lado creador de esa venganza del débil consiste en invertir los valores superiores del fuerte: en transvalorar la fuerza en crueldad; la destructividad intrínseca a la vitalidad, en maldad; la humillación que surge de la impotencia, en virtud. De acuerdo con esta lectura, el juicio inculpatorio de Améry encubriría un móvil bajo - su deseo de venganza - tras el velo de un móvil elevado: restaurar el orden subvertido. «Mi resentimiento existe para exigir que los verdugos paguen con la misma moneda que me hicieron pagar a mí», vendría a decir Améry. Pero ¿es así?

Ciertamente, él no niega que una compensación de esta naturaleza hubiera proporcionado una satisfacción o desagravio a sus sufrimientos. Sin embargo, también dice que esa satisfacción hubiera sido «indigna», y una «sangrienta ilusión» ${ }^{16}$ el desagravio así obtenido. En realidad, lo que Améry reivindica no es el derecho a imponer a los verdugos un castigo que expíe su crimen. Como él dice, «la cuestión no estriba en si he escudriñado a fon- 
do en mi fuero interno, no consiste ni en la venganza ni tampoco en la expiación» ${ }^{17}$. ¿Cuál es, entonces, la cuestión? Para decirlo escuetamente, consiste en que los verdugos y sus cómplices se nieguen a sí mismos como tales, lo cual exige que reconozcan lo que han hecho, que vean lo que se niegan a ver. Conviene recordar que el resentimiento no surgió en Améry en el momento de padecer la violencia, sino al constatar, más tarde, que sus ejecutores y cómplices no asumían su parte de responsabilidad en ella. Eso indica que no surgió como un mecanismo de compensación del daño padecido, sino con miras a exigir el reconocimiento ajeno de su autoría. En lugar, pues, de ser un factor de distorsión, Améry lo convierte en una vía de acceso a una dimensión negada de la realidad. ¿Cuál es esta dimensión?

El genocidio, la tortura, las mutilaciones de toda especie, objetivamente, no son más que cadenas de eventos físicos, descriptibles en el lenguaje formalizado de las ciencias naturales: son hechos en el seno de una teoría física, no actos en el seno de un sistema moral. Los delitos del nacionalsocialismo, ni siquiera para el ejecutor que, sin excepción, se sometía al sistema normativo de su Führer y de su Reich, poseían una cualidad moral. El criminal que no se siente vinculado a su acción por su conciencia, la ve sólo como objetivación de su voluntad, no como fenómeno moral. Wajs, el lacayo de las SS de origen flamenco, alentado por sus amos alemanes, que me golpeaba en la cabeza con el mango de la pala cuando no excavaba lo suficientemente rápido, sentía la herramienta como la prolongación de su mano y los garrotazos como embates de su dinámica psicofísica. Sólo yo estaba, y estoy, en posesión de la verdad moral de los golpes que aún hoy me resuenan en el cráneo $\mathrm{y}$, por tanto, me siento más legitimado a juzgar, no sólo respecto a los ejecutores, sino también a la sociedad que sólo piensa en su supervivencia. La comunidad social no atiende sino a su propia seguridad, y no se deja afectar por la vida dañada: mira hacia delante, en el mejor de los casos para que no se repita algo similar. Mis resentimientos existen con el objeto de que el delito adquiera realidad moral para el criminal, con el objeto de que se vea obligado a enfrentar la verdad de su crimen ${ }^{18}$.

La representación más usual de la relación entre el causante del daño y su víctima descansa en el supuesto de que ambos se hallan en posiciones simétricas, aunque enfrentadas: el uno causa dolor y el otro lo padece, siendo el daño producido la mediación real que los une. El antagonismo de sus posiciones se expresaría en la idea de que, al igual que la víctima se sabe víctima, también el verdugo se sabe verdugo. Esta representación da, pues, por sentado que el verdugo percibe el daño que causa a la víctima. Sin duda, esto es cierto, pero sólo en el sentido trivial de que alguien no puede hacer algo intencionadamente sin darse cuenta de lo que hace. Sin embargo, si nos preguntamos cómo es posible que, a pesar del sufrimiento de la víctima, el verdugo siga torturándola, la respuesta de Améry es que lo hace en tanto que falsea la realidad hasta hacérsele invisible el daño que causa ${ }^{19}$.

El factor determinante de ese falseamiento consiste en situarse en una posición objetivadora: el torturador percibe el golpe que asesta a la víctima como una descarga de energía; evalúa los medios que emplea en función de su eficacia para conseguir los fines deseados; contempla el sufrimiento de la víctima como una reacción analizable en términos de resistencia biológica; se ve a sí mismo como instrumento de una autoridad que le da órdenes. En suma, ve sus actos como fenómenos naturales, como parte de un sistema cuasimecánico. Si nos preguntamos ahora cuál es el punto de vista de la víctima, advertiremos de inmediato la situación asimétrica en que uno y otro se encuentran. El verdugo no ve el daño que causa porque, interesado como está en ocultárselo a sí mismo para poder seguir torturando, se ha situado a una distancia de él que no se da en el caso de la víctima. Desde luego, no es imposible que la víctima se disimule a sí 
misma el daño que recibe, bajo la ilusión de que así obtendrá algún bien superior a su integridad física. Pero si cree que consentir a una ilusión de ese tipo sería una forma de autodegradarse, entonces verá las cosas de otra manera: sentirá el golpe del torturador como un acto de crueldad; experimentará su propio sufrimiento como un daño que la marca indeleblemente; verá a su torturador como un ser humano del que cabe esperar que respete la integridad del prójimo y al que se le pueden exigir responsabilidades por atentar contra ella.

Una forma posible de juzgar filosóficamente la divergencia entre quien causa daño y quien lo padece consiste en reducir sus respectivos puntos de vista a meras interpretaciones. El verdugo y la víctima interpretan la realidad de diferente manera. Si esta aproximación se lleva lo bastante lejos, la idea de una realidad absoluta se esfuma como un residuo evanescente y sólo subsiste como real el conflicto de las interpretaciones. Desde ese momento, cualquier pretensión de resolverlo en términos de verdad se revela absurda.

A esta forma de relativismo se enfrenta otra posición filosófica que apela a la noción de verdad, pero la restringe al dominio particular de la realidad que constituye el objeto específico de la ciencia natural. La perspectiva científica discrimina los rasgos del mundo susceptibles de cálculo, manejo y predicción como los únicos válidos por igual para todos - esto es precisamente lo que define su «objetividad»-, desplazando a otro ámbito de realidad los rasgos que no se ajustan a estos criterios, entre ellos las cualidades morales. Al mismo tiempo, establece una brecha epistemológica entre esos dos planos, al considerar la noción de verdad aplicable al conocimiento natural, pero no al juicio moral. En consecuencia, cuando la perspectiva científica contempla las acciones humanas despojadas de todo rasgo moral, cree verlas tal como objetivamente son. Y como los rasgos morales que atribuimos a esas acciones no forman parte de esa realidad objetiva, sólo pueden explicarse por referencia a algún factor sobrevenido o proyectado sobre ella, que carece de validez universal (y es, en este sentido, «subjetivo»).

Améry describe la relación entre el torturador y la víctima en el lenguaje de la perspectiva científica: atribuye a aquél una descripción de sus actos como «hechos en el seno de una teoría física» y a la víctima una descripción de esos mismos hechos como «actos en el seno de un sistema moral» ${ }^{20}$. Pero sería un error deducir de ahí que mantiene el dualismo epistemológico de la perspectiva científica, pues él atribuye a la visión moral de la víctima un valor de verdad que niega a la visión naturalista del verdugo. En realidad, la perspectiva de Améry es diametralmente opuesta a la del causante del daño (que, aunque sustentada en razones diferentes, coincide materialmente con la perspectiva científica). La descripción de los actos del verdugo como hechos naturales se considera objetiva en tanto que supuestamente refleja lo que esos actos realmente son. Améry, por el contrario, considera que esos actos, como humanos que son, tienen una dimensión moral que es constitutiva de su realidad. Que las personas no son objetos físicos para las personas es un hecho. Que las relaciones humanas sólo son humanas si se basan en actitudes de reconocimiento, cuidado y respeto es otro hecho (o quizás otro aspecto del mismo hecho). Puesto que el concepto de moralidad designa estas y otras cualidades constitutivas de la dimensión humana de la acción social, aquellos hechos son hechos morales. Quien no ve en los rasgos morales una dimensión constitutiva de las acciones y de las relaciones humanas no tiene una visión correcta de ellas, sino una visión distorsionada. Esa visión es el resultado de un rodeo que comienza despojando al mundo de todo rasgo de valor, prosigue considerando ese mundo neutro como realmente objetivo y acaba relegan- 
do los rasgos de valor al ámbito de lo subjetivo (lo no válido para un observador ideal). Lo que hay de distorsionador en esta visión es que, al contemplar los actos humanos como meros eventos naturales, los contempla como no humanos. Pues atribuir a los actos humanos rasgos morales es una condición para atribuirles un contenido humano $y$, por tanto, para acceder a su verdadera realidad.

Como cualesquiera otros hechos, los hechos morales pueden ser vistos o ignorados, reconocidos o deformados, en función de la posición de experiencia en que uno se encuentre. En una relación humana mediada por la violencia y el daño - especialmente, cuando la violencia y el daño cualifican la relación entera, como ocurre en el caso de la tortura - , quien daña puede hacerlo y lo hace en tanto que reduce al otro a una cosa. La posición de verdugo se autoafirma tanto más fácilmente cuanto más lejos va en la ocultación de la realidad moral de sus actos. El mecanismo de ocultación al que Améry alude en su análisis consiste en un movimiento de repliegue en virtud del cual quien daña se retrae desde una posición de participante en una relación humana - pues en esta posición le resulta insoportable dañar - a una posición de mero observador ${ }^{21}$, en la cual puede hacerlo sin costes morales para él y con la coartada de que su visión de la realidad es la objetiva. Pues el colmo de la distorsión consiste en llevarla a cabo en nombre de una teoría del conocimiento que ha convertido la posición del observador externo en tipo ideal del sujeto de conocimiento en general.

Que la realidad moral de la violencia sólo sea vista por la víctima no implica que sea relativa. Implica que sólo la ve adecuadamente quien la mira adecuadamente. $Y$ el verdugo no la ve, porque así puede existir como verdugo sin problemas de conciencia. La ceguera moral del verdugo no puede, sin embargo, resultar indiferente a la víctima. Desde el momento en que ésta sabe, como en el caso de Améry, que esa ceguera ha sido condición necesaria del daño padecido, si la víctima abandonase al verdugo a su ceguera habría renunciado a negar su propia condición de víctima, lo que sería tanto como darla por buena. El resentimiento de Améry contra los verdugos y sus cómplices tiene el significado moral de un aguijón que le azuza para que no se abandone a la tentación del conformismo. Améry se rebela contra la ceguera del verdugo en la misma medida en que se rebela contra su propia condición de víctima. Y como fue aquella ceguera la que le condujo a esta condición, para negarla es necesario que el verdugo vea lo que no ve. Éste es el sentido de su exigencia de traer al presente lo sucedido entre ambos mediante una comparecencia del verdugo ante su crimen, que no puede darse sólo en un plano individual-moral, sino que ha de plantearse en el ámbito de la praxis colectiva e histórica en que ocurrió el crimen ${ }^{22}$.

Cuando Améry conmina al verdugo a que comparezca ante su acto y lo reconozca como crimen no está pidiendo vengan$\mathrm{za}$, ni reclamando una compensación, sino obligándole a que se reintegre al mundo humano del que se excluyó para constituirse en verdugo. Améry se refiere a este restablecimiento de la comunidad moral cuando dice que, al verse enfrentado a la realidad de su crimen, el verdugo deja «de ser enemigo para convertirse de nuevo en prójimo» ${ }^{23}$. Si el verdugo llega a ver la realidad moral de su crimen, se habrá negado como verdugo, al tiempo que habrá negado a la víctima como víctima. Esa negación no neutraliza lo ocurrido entre ambos, ni implica, por consiguiente, un retorno del verdugo al estado original de inocencia y de la víctima al estado anterior al daño. De esa negación forma parte, más bien, que el verdugo integre en el presente su acción pasada en el modo de una actitud de desconfianza con respecto a sí mismo que permita a la víctima confiar 
en la posibilidad de relacionarse con él como un semejante.

De esta manera se cumple lo que Améry llama «la reversión moral del tiempo» ${ }^{24}$. Antes hemos apuntado que la perspectiva clínica trata de lograr que el resentido se libere de la sujeción a su pasado, de manera que pueda orientar su vida hacia el futuro. Esta perspectiva se basa en un sentido natural del tiempo, que ve el pasado como irreversible y considera cualquier intento de revertirlo como un síntoma de insania. De acuerdo con la orientación natural hacia el futuro, el terapeuta considera el paso del tiempo como un posible aliado de cara a liberar a la víctima de la fijación a su pasado, en la confianza de que «el tiempo cura las heridas» ${ }^{25}$. Este modelo biológico está presente también en la concesión social del perdón al delincuente sobre la base del tiempo transcurrido desde la comisión del delito, pues con esa disculpa la sociedad, que mira hacia el futuro y atiende a su bienestar, olvida también la desazón que el crimen le causó.

Améry opone a este sentido biológico y social del tiempo un sentido moral, que se niega a admitir la distancia temporal como principio de prescripción del crimen. La violencia padecida por la víctima es personal, no colectiva; y falsea este hecho elemental cualquier gestión temporal del daño que subordine las necesidades morales de la víctima al bienestar social. Una de las virtualidades que Améry descubre en su resentimiento es que hace valer la irreductible individualidad de la violencia padecida, impidiendo olvidar que el daño de la víctima es imborrable y que, en consecuencia, el crimen del verdugo es imprescriptible. Es falso, por consiguiente, que el paso del tiempo pueda cicatrizar la herida causada por la violencia. También a efectos de no sucumbir a la aparente reordenación de las cosas que el paso del tiempo lleva a cabo y de impedir que todo vuelva por sí mismo a su antiguo cauce, existe el resentimento de Améry. Por lo demás, eso no implica que víctima y verdugo estén uncidos a su condición de tales como a un destino inamovible. La percepción moral del tiempo incluye la posibilidad de revertirlo, $y$, bajo determinadas condiciones, la exigencia de llevar a cabo esa reversión es un síntoma de salud moral. Pero revertir moralmente el tiempo no significa nada que se parezca a deshacer lo hecho. Significa dirimir el conflicto irresuelto entre víctima y verdugo en la forma de una negación pública y continuada por parte del verdugo de todo cuanto hizo posible su crimen. Eso no curará a la víctima del daño padecido, pero rescatará al verdugo de su posición extramoral y a la víctima de su soledad moral, reintegrando a ambos a un mundo humano.

\section{III}

Al considerar la acción del verdugo y el daño de la víctima como hechos morales, Améry lleva su réplica a Nietzsche a un nivel de radicalidad. Para advertirlo, convendrá tener presentes algunos aspectos de la crítica de éste. Con la redacción de Aurora, en 1880, Nietzsche inició una «campaña contra la moral» ${ }^{26}$ que habría de ocupar un lugar destacado en el último periodo de su vida productiva. En la base de su interés se halla la constatación de un fenómeno nuevo: la sobrestimación moderna de la moral de la compasión ${ }^{27}$. Ese fenómeno constituía, a su juicio, un indicio inquietante de la deriva de la cultura europea hacia el nihilismo. A fin de contrarrestar esa tendencia había que emprender una crítica de la moral establecida, y el modo específico de hacerlo consistía en investigar las condiciones bajo las cuales los valores de esa moral surgieron, se desarrollaron y modificaron. La genealogía es el método adoptado por Nietzsche para llevar a cabo tal investigación. El genealogista se enfrenta a la moral vigente desde la actitud crítica que pregunta, no 
por su grado de validez - pues esta forma de crítica presupone la verdad como algo en sí, cuando la crítica nietzscheana cuestiona el valor mismo de verdad-, sino por las conexiones que guarda con quienes la comparten. Pregunta, pues, cómo se ha constituido la moral, a qué necesidades responde, qué decisiones expresa; en suma, de qué tipo humano históricamente determinado es síntoma. Genealogía es lectura del síntoma, desciframiento del significado oculto que subyace a él.

La genealogía pone de manifiesto que la milenaria vigencia de la moral judeocristiana no acredita tanto su verdad como su utilidad adaptativa. El hombre se encontró, desde antiguo, expuesto a una forma de nihilismo teórico-práctico. $\mathrm{La}$ conciencia de su insignificancia en la corriente del devenir cósmico, así como su dificultad para entender y aceptar la existencia del dolor y del mal, eran peligros que amenazaban con privar de todo sentido al mundo y a la vida humana. Al apelar a un Dios creador y providente, el judeocristianismo dio al hombre un valor absoluto, otorgó al mundo un carácter de perfección a pesar del mal y del dolor, e incluso confirió a éstos un sentido al postular la existencia en el hombre del libre albedrío. De este modo, la moral se presentó como un remedio contra aquella primera forma de nihilismo, llegando a legitimarse como una afirmación de valores positivos. Pero la sospecha metódica que Nietzsche adopta frente a lo que se nos ofrece como verdadero orienta su investigación genealógica en la dirección opuesta, para llegar a la conclusión de que esa moral que se presenta como una afirmación de la vida en realidad no es más que su camuflada negación. Lejos de ser un movimiento en favor de los valores más nobles y elevados, es una rebelión contra esos valores.

El desenmascaramiento nietzscheano de la moral se basa en el contraste con un sistema de valores anterior que aquélla vendría a invertir y suplantar. En el comienzo hay la contraposición entre la manera de valorar de los nobles y poderosos, «los hombres de posición superior y elevados sentimientos, quienes se sintieron y se valoraron a sí mismos y a su obrar como buenos» ${ }^{28}$, y la manera de valorar de los hombres vulgares y plebeyos, incapaces de crear valores a partir de sí mismos. Esta contraposición fundamenta una jerarquía entre «una especie superior dominadora en su relación con una especie inferior» ${ }^{29}$. El origen de la antítesis de los valores bueno (gut) y malo (schlecht) se halla en el sentimiento de distancia y superioridad de los dominadores: «bueno» designa lo que nace de ese sentimiento y lo corrobora; «malo» resume los sentimientos opuestos, que se asocian a los dominados.

Es significativo que Nietzsche defina este concepto original de «bueno» en términos de las relaciones de poder y sumisión que se establecen entre señores y siervos. Ciertamente, la manera noble de valorar no se ejerce sólo en la relación con el plebeyo, sino también en las relaciones que el noble mantiene consigo mismo y con sus iguales, sean amigos o enemigos. Así es como «bueno» adquirió los valores de veracidad, valentía, pureza, salud, orgullo, potencia, lucha y respeto al adversario ${ }^{30}$. Pero la fortaleza y la superioridad del noble no se manifiestan solamente en sus relaciones con sus iguales, sino que necesitan ejercitarse también contra los extraños y desiguales, es decir, contra los débiles. El modelo de esta relación es la del animal de rapiña con su presa ${ }^{31}$. El recurso a este modelo revela que para Nietzsche el fuerte ejerce y manifiesta su fortaleza con respecto al débil a través de comportamientos agresivos, pues sólo ellos son auténticamente activos. Dado que «la vida actúa esencialmente, es decir, en sus funciones básicas, ofendiendo, violando, despojando, aniquilando, y no se la puede pensar en absoluto sin ese carácter» ${ }^{32}$, en el esquema conceptual de 
Nietzsche no parece caber la posibilidad de considerar conductas de simpatía o de compasión hacia el débil como expresión original de fortaleza y de vitalidad ${ }^{33}$. Desde «el supremo punto de vista biológicos ${ }^{34}$, la voluntad de ofender, violentar, despojar y aniquilar tiene un derecho absoluto, mientras que las restricciones artificialmente impuestas a esa voluntad sólo pueden llegar a legitimarse en tanto que medios subordinados al fin global de salvaguardarla, por lo que cualquier pretensión de levantar contra ella un orden moral y político supuestamente superior sería antinatural y «hostil a la vida» ${ }^{35}$.

Lo que Nietzsche no ve es que contemplar la violencia humana a través del modelo de la conducta animal conduce a una percepción deformada de su realidad. Como, por contraste con la crueldad del hombre del resentimiento, es posible imaginar que la crueldad de la bestia es una crueldad desinteresada que no destruye a su presa por el móvil negativo de aniquilarla, sino como efecto inmediato de su propia autoafirmación, Nietzsche supone que es posible una forma humana de crueldad - precisamente la de una humanidad superior - tan desinteresada y afirmativa como la de la bestia ${ }^{36}$. Sin embargo, esta visión no humana - externa, naturalista, objetiva - de la crueldad humana impide el acceso a una de sus dimensiones características: su esencial negatividad. Améry dice haber experimentado la crueldad del torturador como surgida de la voluntad de anular radicalmente a la víctima. «En el mundo de la tortura, el hombre subsiste sólo en la destrucción del otro» ${ }^{37}$. De su relato se desprende que esa voluntad de aniquilar al otro no es, como cree Nietzsche, el móvil específico de una forma degenerada de crueldad, sino una dimensión constitutiva de la crueldad, en tanto que forma expresiva y productiva de la relación política de dominación de unos seres humanos sobre otros.

Nietzsche creyó posible -0 , al menos, deseable - un sistema de valoración con- forme al cual la violencia del fuerte sobre el débil fuese considerada más allá de lo bueno y lo malvado: un hecho no enjuiciable en términos de libertad, responsabilidad y culpa, y que sólo admitiría el calificativo de «bueno» en el sentido de ser efecto y expresión de la voluntad de poder de los individuos superiores, manifestación de su voluntad de poder afirmativa. En consecuencia, la consideración de la crueldad del individuo superior como un hecho moral -su valoración como un crimen - no es un dato originario, sino un fenómeno derivado que requiere una explicación. La genealogía de la moral la proporciona, al interpretar aquella valoración moral como una inversión fraudulenta de la valoración original, que tiene su origen precisamente en el resentimiento. El débil que padece la violencia del fuerte la denigra, no porque le sea perjudicial a él, que es incapaz de responder de la misma manera, sino con el argumento de que contraviene un orden autónomo. Cuando el resentido apela a la verdad no pretende sancionar la utilidad que le reporta, sino presentarla bajo el ropaje de un valor en sí que se halla por encima de los hombres y que éstos deben respetar. Así pues, la función distorsionadora del resentimiento se manifiesta, especialmente, en la pretensión de hacer pasar sus valoraciones por juicios acerca de hechos, es decir, acerca de un orden moral real. Por ello, el desenmascaramiento de la moral que la genealogía lleva a cabo sólo concluye al mostrar el carácter ilusorio de esta pretensión:

Es conocida mi exigencia al filósofo de que se sitúe más allá del bien y del mal, de que tenga debajo de sí la ilusión del juicio moral. Esta exigencia se deriva de una intuición que yo he sido el primero en formular: la de que no existen hechos morales. El juicio moral tiene en común con el religioso el creer en realidades que no lo son. La moral es únicamente una interpretación (Ausdeutung) de ciertos fenómenos, dicho de manera más precisa, una interpretación equivocada (Missdeutung) ${ }^{38}$. 
El alcance totalizador de la crítica nietzscheana es inequívoco. No se trata sólo de mostrar que tras los principios y normas de la moral establecida se esconden muchas veces motivaciones opuestas a las reconocidas, sino de desacreditar íntegramente la moral como una gran mentira. El verdadero sentido de la moral estriba en ser una enfermedad y una patraña. Ella se autointerpreta como un signo de plenitud y de fortaleza, y legitima la compasión, el autosacrificio y el sufrimiento como valores que afirman la vida. Pero su sentido es ser un signo de indigencia, de degeneración y de renuncia a sí mismo. La moral es una mera creación humana puesta al servicio de una determinada voluntad de poder: la de los miedosos y los despreciadores de la vida, la de los débiles y los impotentes. Por ello su auténtica clave y su secreto está en una forma pasiva y decadente de nihilismo que Nietzsche considera absolutamente despreciable.

$\mathrm{Si}$ ahora dirigimos nuestra atención hacia Améry y contemplamos desde la perspectiva de la genealogía de la moral el análisis que hace de su propia experiencia como víctima de la violencia, se impone la conclusión de que Améry padece una ilusión. Él afirma estar en posesión de una verdad moral cuando responsabiliza al verdugo del daño que le inflige. Afirma, además, que el verdugo se falsea a sí mismo esa realidad al no querer ver el valor moral de su acción. El punto de vista de Améry presupone, pues, que la libertad y la responsabilidad son rasgos inherentes a la realidad moral de las acciones, y que la moralidad es una dimensión constitutiva de la acción social. También supone, en consecuencia, que el golpe que descarga el verdugo sobre su víctima y el daño que ésta padece son hechos morales, de manera que negar esto implicaría barrer de esa relación aquello que la caracteriza como una relación humana.
Nietzsche afirma, por el contrario, que no se cumplen las condiciones que harían verdadera la visión de Améry, pues no hay ninguna instancia normativa e independiente de la voluntad de los individuos que pueda justificar sus juicios morales. Libertad y responsabilidad no son cualidades reales de las acciones humanas, sino ficciones de los débiles en tanto que se sienten ofendidos por los fuertes ${ }^{39}$. Cuando Améry acusa al verdugo y le exige que reconozca la verdad moral de su crimen, estaría exigiéndole que vea algo que no existe. Por tanto, si el verdugo no reconoce su crimen, muy bien podría hacerlo desde una posición de verdad ${ }^{40}$. Los juicios morales de Améry no tienen el sentido que él les atribuye, pues no existen los hechos morales que los harían verdaderos. Eso no implica que carezcan de todo sentido. Pero el único que la genealogía nietzscheana les reconoce es el de ser síntomas de otros hechos que no son morales. De lo que hablaría en realidad la acusación del verdugo por parte de la víctima es del resentimiento de ésta, de su sed de venganza, de su impotencia para devolver el golpe, así como de su necesidad de encubrir toda esta miseria bajo el manto de un orden de valores supuestamente objetivos que le otorgue respetabilidad.

Sin embargo, el análisis de Améry constituye una refutación, punto por punto, de esta interpretación inspirada en Nietzsche. Es falso, para empezar, que su juicio moral sea un mecanismo encubridor de resentimiento, pues él lo confiesa abiertamente y lo asume, a pesar del coste que tiene para su paz interior. Es falso que Améry necesite mantener abierto el recuerdo de la ofensa como una deuda insaldable para poder justificar una hostilidad permanente hacia el verdugo, pues su resentimiento está dirigido a confrontar al verdugo con su crimen a fin de cerrar el conflicto que existe entre ambos. Es falso que el resentimiento de Améry sea una 
expresión de impotencia, pues su objetivo no es compensar imaginariamente su propio daño, sino exigir a sus autores y colaboradores que asuman públicamente su participación en él. Es falso que esta reactualización del conflicto sea un acto de venganza, pues busca reintegrar al verdugo al mundo humano del que se ha sustraído. Por último, es también falso que la inconsciencia del verdugo acerca del significado moral de su acción manifieste una posición de verdad, pues Améry puede dar razón de ella como una ceguera inducida por mecanismos de distorsión que permiten al verdugo y a quienes tienen noticia de la violencia seguir ejerciéndola o asistiendo a ella sin mala conciencia.

El sentido de la réplica de Améry a Nietzsche no es rehabilitar el sistema de valoración de la moral establecida. Améry se halla tan lejos como Nietzsche de la glorificación del sufrimiento, de la santificación del perdón, de la moral de la culpa y la expiación. Pero así como Nietzsche consideraba que estas actitudes eran producto del rencor, Améry hace valer su resentimiento para enfrentarse a ellas. Al derivar la moral decadente del resentimiento,
Nietzsche atribuye a éste una virtualidad esencialmente distorsionadora. La réplica de Améry se orienta a mostrar que el resentimiento de la víctima de la violencia puede convertirse en un instrumento de verdad y ponerse al servicio de una moral que se sitúa más allá de la culpa y la expiación.

La genealogía nietzscheana de la moral contiene intuiciones brillantes y profundas sobre la función distorsionadora de ciertos conceptos clave de nuestro sistema moral y, en esa medida, puede resultar un medio eficaz de crítica cultural. Pero no atrapa la experiencia de Améry. Cuanto más se le impone al lector la evidencia de que la reflexión de Améry revela la verdad de su experiencia, más firme se hace también la convicción de que Nietzsche sólo logró ver la violencia que se produce en las relaciones entre dominadores y dominados bajo el prisma de un esquema conceptual objetivador y abstracto que se muestra incapaz de dar cuenta de la dimensión de verdad que puede tener el resentimiento de la víctima de la violencia como factor desenmascarador de su esencial negatividad ${ }^{41}$.

\footnotetext{
1 G. Deleuze, Nietzsche y la filosofía, traducción de Carmen Artal, Barcelona, Anagrama, 1994, pp. 7-8.

2 S. Dagerman, Otoño alemán, traducción de José M. ${ }^{\mathrm{a}}$ Caba, Barcelona, Octaedro, 2001, pp. 30-31.

3 J. Améry, Más allá de la culpa y la expiación. Tentativas de superación de una víctima de la violencia, edición de Enrique Ocaña, Valencia, Pre-Textos, 2001, p. 144 (en lo sucesivo se citará por las siglas $C E$ ).

${ }^{4} C E$, p. 146.

5 Ibid.

${ }^{6}$ Cf. $C E$, p. 142.

${ }_{7}$ «No puedo ni quiero superar mis resentimientos, he de vivir con ellos y estoy obligado a explicarlos a aquellos contra los que están dirigidos» ( $C E, \mathrm{pp} .146-$ 147).

${ }^{8} C E$, p. 142

${ }^{9} \mathrm{CE}$, p. 148.
}

10 «A quien soñaba con la síntesis del bárbaro y del superhombre, deben darle réplica aquellos que fueron testigos de la fusión del monstruo y del subhombre» (CE, p. 147).

"Cf. F. Nietzsche, La genealogía de la moral, edición de A. Sánchez Pascual, Madrid, Alianza, 1997, p. 46 (se cita por las siglas $G M$ ).

12 Améry, $C E$, p. 140.

${ }_{13}$ Cf. P. Levi, Si esto es un hombre, traducción de Pilar Bedate, Barcelona, Muchnik, 1995, pp. 195-196; J. Semprún, La escritura o la vida, Barcelona, Tusquets, 1997, pp. 212 y 244.

14 Améry, $C E$, p. 160.

is Nietzsche, $G M$, p. 50 . Améry cita explícitamente este pasaje de la obra de Nietzsche.

${ }^{16} \mathrm{CE}, \mathrm{p} .150$.

$17 C E$, p. 151 . Y más adelante: «Sin duda, tal exteriorización y actualización no pueden consistir en una 
venganza que sea proporcional al sufrimiento padecido [...] Queda excluida como solución tanto la venganza como la expiación, que se me antoja problemática» (pp. 160-161)

18 CE, pp. 150-151.

19 En su análisis de la tortura, Elaine Scarry ofrece una explicación plausible del mecanismo en virtud del cual llega a producirse esta invisibilidad. En la tortura, el acto físico de infligir dolor va acompañado habitualmente de un acto verbal (las preguntas del torturador y las respuestas de la víctima). Según Scarry, el verdadero objetivo del interrogatorio es desviar la atención del torturador $-\mathrm{y}$ de quien tenga noticia de la tortura - desde el acto físico hacia el aspecto verbal, a fin de representarse equivocadamente la pregunta como el «motivo» que justifica la crueldad del torturador ante la respuesta del torturado, representada a su vez equivocadamente en términos de «traición». El proceso verbal logra, así, invertir e sentido del acto físico: frente a la reacción inmediata de repulsión que la inflicción de dolor suscitaba o podía suscitar en el torturador y en el observador, e interrogatorio bloquea esa respuesta al redirigir la atención desde el cuerpo hacia la voz, produciendo en el torturador un efecto exculpatorio, al tiempo que inculpa a la víctima. Esta inversión hace posible que el daño que causa a la víctima se torne invisible para el verdugo y para el observador, pudiendo seguir infligiéndolo $o$ asistir a él sin problemas de conciencia (cf. E. Scarry, The Body in Pain. The Making and Unmaking of the World, Nueva York-Oxford, Oxford University Press, 1985, pp. 35-36)

20 Améry, $C E$, p. 150.

${ }_{21}$ Sobre la dialéctica entre ambas posiciones, véase N. Elias, Compromiso y distanciamiento, Barcelona, Península, 1990.

${ }^{22}$ Sobre la dimensión colectiva de la reactualización del conflicto entre víctimas y verdugos, Améry observa que «podría dirimirse logrando que en un bando se conserve el resentimiento y en el otro se despierte, gracias a este afecto, una actitud de desconfianza respecto de sí mismos» ( $C E$, p. 161). En este sentido, Améry considera que la asunción colectiva de ese «patrimonio negativo» (p. 162) podría «reemplazar a la incumplida revolución alemana» (p. 160). Si es posible alguna salvación, alguna extinción de la ignominia para el pueblo alemán, es a través de que rechace «todo, sin excepción, cuanto llevó a cabo en los días de su más profundo envilecimiento, sin excluir los logros más aparentemente inofensivos, como la construcción de autopistas» (pp. 162-163). Sólo esta negación total haría objetivamente superfluo el resentimiento de las víctimas.

${ }^{23} C E$, p. 151. Claude Eatherly, el piloto de guerra norteamericano responsable del lanzamiento de la bomba atómica sobre Hiroshima, que tras la guerra sintió la enorme responsabilidad que pesaba sobre su conciencia y convirtió su sentimiento de culpa en un arma moral contra la carrera armamentística de las potencias vencedoras, recibió en julio de 1959 una carta de una asociación de víctimas del bombardeo, en que le decían: «Hemos aprendido a sentimos frente a usted como camaradas, y le consideramos una víctima de la guerra como nosotras» (C. R. Eatherly y G. Anders, Más allá de la conciencia, traducción de Adolfo Moreno, Barcelona, Argos, 1962, p. 43). En esa confesión se refleja el reconocimiento de una projimidad que está muy por encima del perdón.

${ }_{24} C E$, p. 153

$25 C E$, p. 152

${ }_{26}$ F. Nietzsche, Ecce homo, edición de A. Sánchez Pascual, Madrid, Alianza, 1971, p. 87. De ese programa forman parte Más allá del bien y del mal (1886), La genealogía de la moral (1887), Crepúsculo de los idolos (1888) y El Anticristo (1888), así como un conjunto significativo de textos póstumos.

27 Cf. Nietzsche, $G M$, p. 27.

${ }^{28} G M$, p. 37

${ }_{29} G M$, p. 38

${ }^{30} \mathrm{Cf} . G M$, pp. 41 ss.

31 Cf. $G M$, pp. $54-55$ y 59

32 GM, p. 98

33 Polemizando con Nietzsche, Max Scheler ha argumentado que el cuidado del otro puede ser una manifestación de genuina vitalidad y fortaleza: «Existe un impulso al sacrificio en pro de seres con los cuales nos sentimos unos y solidarios, en oposición a todo lo "muerto", mediante el don (propio de todo viviente) de simpatizar con otro viviente, don graduado según la cercanía y homogeneidad de ese viviente. $\mathrm{Y}$ dicho impulso no es, en modo alguno, algo que la vida adquiere, algo que pueda derivarse de impulsos primitivamente egoístas, sino que es originalmente propio de la vida» (M. Scheler, El resentimiento en la moral, trad. de J. Gaos, Madrid, Caparrós, 1998, pp. 67-68).

34 Nietzsche, $G M$, p. 98

35 GM, p. 99

36 «Repugna, me parece, a la delicadeza y más aún a la tartufería de los mansos animales domésticos (quiero decir, de los hombres modernos, quiero decir, de nosotros) el representarse con toda energía que la crueldad constituye en alto grado la gran alegría festiva de la humanidad más antigua [...]; el imaginarse que por otro lado su imperiosa necesidad de crueldad se presenta como algo muy ingenuo, muy inocente, $y$ que aquella humanidad establece por principio que precisamente la «maldad desinteresada» [...] es una propiedad normal del hombre» $(G M$, p. 86$)$

${ }^{37}$ Améry, $C E$, p. 101

38 F. Nietzsche, Crepúsculo de los ídolos, edición de A. Sánchez Pascual, Madríd, Alianza, 1979, p. 71.

${ }^{39}$ Sobre la idea de sujeto y sus determinaciones morales de libertad y responsabilidad, en cuanto falsa interpretación de la debilidad, véase $G M, 1, \S 13$.

40 Es secundario, a efectos del argumento, decidir si los torturadores de Améry encajan o no, de hecho, 
bajo la noción nietzscheana del individuo fuerte y superior.

${ }^{41}$ Este ensayo germinó en un seminario de doctorado sobre el tema «La verdad en la experiencia del daño», impartido con Josep Corbí. Colaborar con él ha sido para mí, a lo largo de la redacción del artículo, un estímulo constante de ánimo y de clarificación intelectual por el que le estoy profundamente agradecido. También quiero agradecer sus observaciones a Ana Escribá, Enrique Ocaña y Joan B. Llinares. 